\section{Defensive medicine: Spiraling costs}

The editorial pages of this and other medical publications have pointed out with varying degrees of intensity that the practice of defensive medicine has been a major contributing factor to the rising costs of medical care.

A recent study ${ }^{1}$ reported in The Journal of the American Medical Association estimates that medical professional liability costs in 1984 accounted for 15 percent of total expenditures on physicians' services, with much of the cost paid to defensive practice changes prompted by malpractice risks.

The study, conducted by Roger A. Reynolds, Ph.D., John A. Rizzo, Ph.D., and Martin L. Gonzalez, M.S., of the AMA's Department of Medical Practice Economics, Center for Health Policy Research, reports that the risk for the average physician of incurring a malpractice claim has nearly tripled since 1980 , with indications that increases in the severity of losses have accelerated as well. The researchers say that the problem is of growing public and professional concern, but "to date there has been little quantitative evidence on the overall economic impact of the problem."

In the JAMA editorial ${ }^{2}$ concerning the Reynolds' report, it is stated that average malpractice insurance premiums rose by an estimated $\$ 1,300$ to $\$ 8,400$ annually from 1983 to 1984 . Concurrently, perceived increases in malpractice risks caused physicians to increase defensive medical procedures, at an additional average cose of $\$ 4,600$ per physician per year.

The increase in defensive medicine costs was more than 3.5 times the parallel increase in malpractice insurance premiums. That is, for each $\$ 100$ spent on malpractice risk-gauged by insurance premiums - $\$ 3.50$ are expended for defensive medicine. "Hence, the average physician who paid $\$ 8,400$ in malpractice premiums for 1984 was responsible for a total annual health care expenditure of $\$ 30,000$ for defensive medicine."

Whether the practice of defensive medicine will have a major impact on the cost of professional liaibility insurance or a reduction in claims is problematic. Until the public is made to realize the true nature of the medical professional liability crisisits bottom-line effect-defensive medicine will con- tinue to be practiced to greater and greater degrees. Logical, rational controls of the situation will somehow be achieved. At the present time, unfortunately, it's a runaway problem.

GEORGE W. NORTHUP, D.O., FAAO

1. Reynolds, R.A., Rizzo, J.A., and Gonzales, M.L.: The cost of medical professional liability. JAMA 257:2776-81, 22/29 May 87 2. Harris, J.E.: Defensive medicine. It costs, but does it work? (editorial). JAMA 257:2801-2, 22/29 May 87

\section{We need you!}

A colleague of mine once raised two questions in quick succession: "Who cares whether I am an AOA member or not? So who misses me?"

The 24,443 members of the American Osteopathic Association, that's who! We care, and we need you!

We need you because your presence strengthens the organization and your absence weakens it.

We need you because your ideas, your needs, and your help are important. And because we need each other. The American Osteopathic Association can be a protector, a supporter, and an advisor. Although the AOA is the sole representative of the entire profession in the United States, its greater service is through its membership, not nonmembership.

We need you in order to serve the public better.

As a member of the osteopathic profession, you are represented by the American Osteopathic Association. In making policy, it helps to create the environment in which you live your professional life. You practice under acts that your state and national organizations help to develop. Hospitals, general practitioners, and specialists maintain standards of service that are spelled out by your national association. It is your organization, yet some of you are not a part of it.

It would be naive to believe that every member and nonmember agrees with all that the AOA does and has done. Many of us have not always agreed, and that is one reason why we belong. Individuals are guilty of errors of commission and omission, and organizations are collections of individuals that are capable of making the same errors. The 